\title{
Evaluation of antimicrobial susceptibility of Escherichia coli strains isolated in Rabat University Hospital (Morocco)
}

\author{
Nabil Alem ${ }^{1,2,4^{*}}$, Mohammed Frikh ${ }^{1,2}$, Abdellatif Srifi ${ }^{2}$, Adil Maleb ${ }^{3}$, Mariama Chadli1,2, Yassine Sekhsokh ${ }^{1,2}$, \\ Lhoucin Louzi ${ }^{2}$, Azzedine Ibrahimi ${ }^{2}$, Abdelhay Lemnouer ${ }^{1,2}$ and Mostafa Elouennass ${ }^{1,2}$
}

\begin{abstract}
Background: Escherichia coli (E. coli) is the most commonly isolated bacteria in human pathology. In Morocco the data concerning the nature and the rates of antibiotic resistance of E. coli in both hospitals and city environment remains relatively poor and needs further investigations.

Methods: During a 16 months period, E. coli isolates were collected from different culture specimens received in the Bacteriology Department of the Military teaching Hospital Mohammed-V-Rabat for routine diagnostic purposes. E. coli isolates were identified and their antimicrobial susceptibility pattern was determined.

Results: A total of 1369 E. coli isolates comprising $33 \%$ (1369/4110) of culture-positive samples were consecutively collected. Isolates of E. coli were, in $40.5 \%$ (554/1369) of cases from hospitalized patients and in $59.5 \%(815 / 1369)$ of cases from outpatients. Urine isolates represented $82 \%(1123 / 1369)$ of the cases. High rates of resistance were found for amoxicillin (42.5\%), cefalotin (30.4\%), norfoloxacin (29.9\%) and sulfamethoxazole (37.7 \%). The detection rate of ESBL was $6.1 \%$ (85/1369). In hospitalized patients $11.9 \%$ of the isolates of E. coli (66/554) had an ESBL phenotype while in outpatients cases only $2.3 \%$ of isolates of E. coli (19/815) had this phenotype.

Conclusions: Our findings suggest that more judicious use of antibiotics is needed especially in probabilistic treatment. The emergence of ESBL in the Moroccan cities is an indicator of the severity of this problem that is not limited to health care facilities.
\end{abstract}

Keywords: Escherichia coli, Antimicrobial susceptibility, Morocco

\section{Background}

Escherichia coli (E. coli) is a common commensal of the intestine of humans and animals but can also be found in water, soil and vegetation [1]. It is the most frequently isolated bacteria from clinical samples [1], indeed E. coli is the pathogen most involved in urinary tract infections [2-4] and one of the common agents responsible for ear infections, sepsis and wound infections $[5,6]$. In the developing countries, E. coli represents the agent most commonly responsible for food and waterborne diarrhea

*Correspondence: nabil_alem86@hotmail.fr

${ }^{4}$ villa 96 la corniche hay el fath, Rabat, Morocco

Full list of author information is available at the end of the article and causes high mortality in children under 5 years old [7].

Escherichia coli dominates the overall spectrum of the bacterial infections in both hospitals and the community [8]. Therefore its susceptibility to antibiotics reflects both the hospital and community antibiotic selection pressure [9].

The emergence of resistance is a global phenomenon, although the rates of antibiotic resistance remain different between developed and developing countries $[10,11]$. This emergence complicates the management of infections and impacts the use of widely prescribed antibiotics in clinical practice such as penicillins, sulfonamides and fluoroquinolones. 
The aim of this study is to determine the resistance rate of $E$. coli isolates to different antibiotics in the Rabat Military Teaching Hospital Mohammed V and to compare these rates of resistance between hospitalized patients and outpatients and between urine isolates and other isolates.

\section{Methods \\ Materials}

The present study was conducted in the bacteriology department of the Rabat Military Teaching Hospital Mohammed V. Retrospectively from April 1, 2012 to July 31, 2013. We included all E. coli isolates received from hospitalized patients and outpatients. We highlight that under Moroccan law no ethical approval is required for a retrospective study based on laboratory data and no consent from patients is necessary to carry out further tests on samples collected for other purposes.

In order to eliminate duplicates, only one strain isolated from the same patient with the same antibiotic susceptibility was included.

\section{Bacterial identification and antimicrobial susceptibility}

The identification of bacterial isolates was based on cultural, morphological and biochemical characteristics. Biochemical identification was set up using API20E (bioMérieux SA, Marcy-l'Étoile/France).

Antibiotic susceptibility was determined using the agar diffusion method (Mueller-Hinton medium) and its interpretation was made according to the recommendations of antibiogram committee of the French Society for Microbiology [12].

Antibiotics tested were: amoxicillin-clavulanic acid, cephalothin, cefoxitin, ceftriaxone, ertapenem, gentamicin, amikacin, norfoloxacin, cotrimoxazole and fosfomycin.

Detection of extended $\beta$-lactamases (ESBL) was performed by phenotypic method based on the detection of synergy between amoxicillin-clavulanic acid disc and three discs of third-generation cephalosporins: cefotaxim, ceftazidime and cefepime [12].

\section{Statistical analysis}

The Chi square test was used to compare resistance rates. The difference between the frequencies was considered to be significant when $p$ was $<0.05$.

\section{Results}

During the period of our study, were received at the bacteriology department a total of 32,522 samples. The sex ratio male/female was $1.03(16,515 / 16,007)$. The rate of urine samples was $25.09 \%(8159 / 32,522)$ with a sex ratio male/female $0.73(3459 / 4700)$. The overall incidence of isolation of $E$. coli was $33.3 \%(1369 / 4110)$. The sex ratio male/female was 0.65 (538/830). Isolates of $E$. coli were in $40.5 \%(554 / 1369)$ of cases from hospitalized patients and in $59.5 \%(815 / 1369)$ of cases from outpatients. Urine isolates represented $82 \%$ $(1123 / 1369)$ of the cases.

Isolates with ESBL phenotype represented $6.1 \%$ of all E. coli isolates (85/1369). In hospitalized patients $11.9 \%$ of the isolates of E. coli $(66 / 554)$ had an ESBL phenotype while in outpatients cases only $2.3 \%$ of isolates of E. coli $(19 / 815)$ had this phenotype. Furthermore $84.4 \%$ $(43 / 66)$ of the isolates with ESBL phenotype in hospitalized patients were also resistant to fluoroquinolones (FQ resistance + ESBL).

High rates of resistance were found for amoxicillinclavulanic acid (42, $5 \%)$, cefalotin $(30,4 \%)$, norfoloxacin $(29,9 \%)$ and cotrimoxazole (37, $7 \%)$.

Table 1 shows the rates of resistance $(\mathrm{R}+\mathrm{I})$ within $E$. coli isolates depending on the nature of patients. Frequencies of resistance among isolates from hospitalized patients were higher than those from outpatients in the case of: amoxicillin-clavulanic acid ( $p<0.001)$, cephalothin ( $\mathrm{p}<0.001)$, cefoxitin $(\mathrm{p}=0.001)$, ceftriaxone $(\mathrm{p}<0.001)$, amikacin $(\mathrm{p}=0.001)$ and norfoloxacin $(\mathrm{p}=0.003)$.

Table 2 shows the rates of resistance $(\mathrm{R}+\mathrm{I})$ of $E$. coli isolates depending on the nature of sample. Frequencies of resistance among isolates from urine samples were lower than those from others samples in the case of: amoxicillin-clavulanic acid $(\mathrm{p}<0.001)$, cephalothin $(\mathrm{p}<0.001)$, cefoxitin $(\mathrm{p}=0.004)$, ceftriaxone $(\mathrm{p}<0.001)$, gentamicin $(\mathrm{p}<0.001)$ and amikacin $(\mathrm{p}<0.001)$.

The rate of simultaneous resistance to all of the three antibiotics which are most used orally $(\mathrm{AMC}+\mathrm{SXT}+\mathrm{FQ})$ was $8.3 \%$ in isolates from hospitalized patients compared to $9.9 \%$ outpatients $(p=0.34)$.

\section{Discussion}

In our study $E$. coli represented over a third of the total isolates of our department. Urinary tract remains the main site of colonization-infection totaling about $82 \%$ of all isolates. These proportions are similar to those found in French and European epidemiological studies [13, 14].

We recorded important levels of resistance $(R+I)$ for amoxicillin-clavulanic acid (38\% in outpatients and $48.1 \%$ in hospitalized patients) these percentages of resistance are comparable to those of Onerba-Francewith $36 \%$ in city and $45 \%$ in hospital [15]. Rates of resistance $(\mathrm{R}+\mathrm{I})$ for $\mathrm{AMC}$ in hospitalized patients were higher than those from outpatients $(\mathrm{p}<0.001)$.

ESBL and resistance to fluoroquinolones are the two most worrying phenomena [16]. A review of Moroccan data shows varying levels of frequency of ESBL by region, 
Table 1 Rates of resistance $(R+I)$ of Escherichia coli isolates depending on the nature of patients

\begin{tabular}{|c|c|c|c|c|c|c|}
\hline & \multirow[t]{2}{*}{ Isolates $n$} & \multicolumn{2}{|c|}{ Out patients $(R+I)$} & \multicolumn{2}{|c|}{ Hospitalized patients $(R+I)$} & \multirow[t]{2}{*}{$p$} \\
\hline & & $n$ & $\%$ & $n$ & $\%$ & \\
\hline Cefalotin (KF) & 1263 & 196 & 26.1 & 185 & 36.2 & $<0.001$ \\
\hline Cefoxitin (FOX) & 1256 & 22 & 2.9 & 34 & 6.7 & 0.001 \\
\hline Ceftriaxone (CRO) & 1032 & 28 & 4.0 & 32 & 9.8 & $<0.001$ \\
\hline Ertapenem (ERT) & 1251 & 14 & 1.9 & 17 & 3.4 & 0.098 \\
\hline Gentamicin (GEN) & 1137 & 66 & 9.8 & 63 & 13.6 & 0.044 \\
\hline Amikacin (AK) & 1250 & 4 & 0.5 & 14 & 2.8 & 0.001 \\
\hline Norfoloxacine (NOR) & 1020 & 182 & 26.1 & 113 & 35.1 & 0.003 \\
\hline Cotrimoxazole (SXT) & 1244 & 261 & 35.2 & 195 & 38.8 & 0.203 \\
\hline Fosfomycin (FOS) & 1082 & 13 & 2.0 & 9 & 2.1 & 0.974 \\
\hline
\end{tabular}

Table 2 Rates of resistance $(R+I)$ of Escherichia coli isolates depending on the nature of samples

\begin{tabular}{|c|c|c|c|c|c|}
\hline & \multicolumn{2}{|c|}{ Urine $(R+I)$} & \multicolumn{2}{|c|}{$\begin{array}{l}\text { Other sam- } \\
\text { ples }(R+I)\end{array}$} & \multirow[t]{2}{*}{$p$} \\
\hline & $n$ & $\%$ & $n$ & $\%$ & \\
\hline Amoxicillin/clavulanic ac (AMC) & 422 & 38.8 & 135 & 56.7 & $<0.001$ \\
\hline Cefalotin (KF) & 292 & 26.9 & 103 & 43.1 & $<0.001$ \\
\hline Cefoxitin (FOX) & 40 & 3.7 & 19 & 8.0 & 0.004 \\
\hline Ceftriaxone (CRO) & 60 & 5.6 & 50 & 21.3 & $<0.001$ \\
\hline Ertapenem (ERT) & 26 & 2.4 & 4 & 1.7 & 0.516 \\
\hline Gentamicin (GEN) & 90 & 9.2 & 38 & 17.7 & $<0.001$ \\
\hline Amikacin (AK) & 7 & 0.7 & 10 & 4.2 & $<0.001$ \\
\hline Norfoloxacine (NOR) & 313 & 29.1 & 74 & 31.2 & 0.52 \\
\hline Cotrimoxazole (SXT) & 398 & 37.2 & 92 & 38.8 & 0.648 \\
\hline Fosfomycin (FOS) & 18 & 1.9 & 4 & 2.1 & 0.779 \\
\hline
\end{tabular}

structures and the size of the populations studied. These rates vary between 7 and $15 \%[17,18]$.

Our study showed a $12.4 \%$ rate of ESBL E. coli in hospitalized patients, this rate remains similar to that recorded by a recent study in Rabat [17] and lower than the one recorded in Khartoum-Soudan [8]. ESBL is not limited to health care facilities; international studies show that in community setting rates of ESBL E. coli range from 1.3 to $4.8 \%$ [19-21]. We recorded a $2.5 \%$ rate of ESBL E. coli in our outpatients.

Fluoroquinolone resistance is associated with the misuse of these molecules in human and veterinary medicine [22]. This resistance varies from one geographic area to another with $10 \%$ in France and United States vs. $40 \%$ in China [15, 23, 24].

Our study found a rate of resistance of E. coli to fluoroquinolones $29.9 \%$ which is similar to that recorded in Rabat [17] with a frequency of resistance among isolates from hospitalized patients higher than those from outpatients $(\mathrm{p}=0.003)$.

A frequent association between genetic determinants of Qnr and those of ESBL was reported by several studies [25]. In our study we found 43 multiresistant strains (ESBL + FQ resistance), more genetic studies are needed to characterize the nature of fluoroquinolone resistance determinants carried by these strains.

The rate of resistance to aminoglycosides remains relatively low (gentamicin $11.1 \%$, amikacin $1.3 \%$ ) as reported in the literature [8]. Amikacin appears to be the most effective molecule of this class of antibiotics explained by the fact that it is strictly used in hospitals and is rarely used in the first line therapy.

In our study, fosfomycin remains largely active on isolates of $E$. coli with low resistance rates especially among urine isolates $(1.9 \%)$. These results suggest that we should favor the use of fosfomycin as a molecule for the empirical treatment of community urinary infections.

\section{Conclusion}

Periodic monitoring of antibiotic resistance in different bacterial isolates has become essential given the constant evolution of the bacterial ecology and the emergence of antibiotic resistance. The high rate of multiresistance shown in this study should encourage us to be more judicious in the use of antibiotics especially in probabilistic treatment. Indeed the $10 \%$ threshold of resistance is substantially exceeded for several antibiotics used in our hospital. The emergence of ESBL in the community is an indicator of the seriousness of this problem which appears not to be limited to health care facilities.

\section{Abbreviations}

AMC: amoxicillin/clavulanic ac; AK: amikacin; CRO: ceftriaxone; E. coli:

Escherichia coll; ERT: ertapenem; ESBL: extended spectrum beta lactamase; FQ: 
fluoroquinolon; FOS: fosfomycin; FOX: cefoxitin; GEN: gentamicin; KF: cefalotin; NOR: norfoloxacin; Onerba: Observatoire National de l'Epidémiologie de la Résistance; SXT: cotrimoxazole.

\section{Authors' contributions}

NA collated the data and prepared the manuscript. MF and AL supervised the project. AS performed the statistical analysis. AM, CM, YS and LL performed the relevant literature search. Al reviewed the article for relevance. ME study conception and design. All authors read and approved the final manuscript.

\section{Author details}

${ }^{1}$ Hôpital Militaire d'Instruction Mohammed V, Rabat, Morocco. ${ }^{2}$ Faculté de Médicine et de Pharmacie de Rabat Université Mohammed V Souissi, Rabat, Morocco. ${ }^{3}$ Faculté de Médecine de Pharmacie d'Oujda Université Mohammed I, Oujda, Morocco. ${ }^{4}$ villa 96 la corniche hay el fath, Rabat, Morocco.

\section{Acknowledgements}

We thank all the staff of the bacteriology department of the Mohammed $V$ military teaching hospital.

\section{Compliance with ethical guidelines}

\section{Competing interests}

The authors declare that they have no competing interests.

Received: 21 April 2014 Accepted: 24 August 2015

Published online: 30 August 2015

\section{References}

1. Lobel B, Valot A, Cattoir V, Lemenand O, Gaillot O. Comparison of antimicrobial susceptibility of 1,217 Escherichia coli isolates from women with hospital and community-acquired urinary tract infections. Presse Med. 2008;37(5 Pt 1):746-50. doi:10.1016/jlpm200705038 (Epub 2008 Mar 7).

2. De Francesco MA, Ravizzola G, Peroni L, Negrini R, Manca N. Urinary tract infections in Brescia, Italy: etiology of uropathogens and antimicrobial resistance of common uropathogens. Med Sci Monit. 2007;13(6):BR136-44.

3. Kashef N, Djavid GE, Shahbazi S. Antimicrobial susceptibility patterns of community-acquired uropathogens in Tehran, Iran. J Infect Dev Ctries. 2010;4(4):202-6.

4. Wagenlehner FM, Naber KG, Weidner W. Rational antibiotic therapy of urinary tract infections. Med Monatsschr Pharm. 2008;31(10):385-90 (quiz 391-2).

5. Biedenbach DJ, Moet GJ, Jones RN. Occurrence and antimicrobial resistance pattern comparisons among bloodstream infection isolates from the SENTRY Antimicrobial Surveillance Program (1997-2002). Diagn Microbiol Infect Dis. 2004;50(1):59-69.

6. Naheed AK, Noor US, Abdus S, Ali Abbas Q. Incidence and antibiogram patterns of Escherichia coli isolated from various clinical samples from patients at N.I.H. Islamabad. Pak J Biol Sci. 2002;5(1):111-3.

7. Turner SM, Scott-Tucker A, Cooper LM, Henderson IR. Weapons of mass destruction: virulence factors of the global killer enterotoxigenic Escherichia coli. FEMS Microbiol Lett. 2006;263(1):10-20.

8. Ibrahim ME, Bilal NE, Hamid ME. Increased multi-drug resistant Escherichia coli from hospitals in Khartoum state, Sudan. Afr Health Sci. 2012;12(3):368-75.

9. Bean DC, Krahe D, Wareham DW. Antimicrobial resistance in community and nosocomial Escherichia coli urinary tract isolates, London 2005-2006. Ann Clin Microbiol Antimicrob. 2008;7:13. doi:10.1186/1476-0711-7-13.
10. Bell JM, Turnidge JD, Gales AC, Pfaller MA, Jones RN. Prevalence of extended spectrum beta-lactamase (ESBL)-producing clinical isolates in the Asia-Pacific region and South Africa: regional results from SENTRY Antimicrobial Surveillance Program (1998-99). Diagn Microbiol Infect Dis. 2002;42(3):193-8.

11. El Kholy A, Baseem H, Hall GS, Procop GW, Longworth DL. Antimicrobial resistance in Cairo, Egypt 1999-2000: a survey of five hospitals. J Antimicrob Chemother. 2003;51(3):625-30.

12. Soussy JC. Recommandation du Comité de l'antibiogramme de la société française de microbiologie. 2011.

13. Chomarat M. Resistance of bacteria in urinary tract infections. Int J Antimicrob Agents. 2000;16(4):483-7.

14. Kahlmeter G. An international survey of the antimicrobial susceptibility of pathogens from uncomplicated urinary tract infections: the ECO.SENS Project. J Antimicrob Chemother. 2003;51(1):69-76.

15. L'observatoire national de l'épidemiologie de la resistance aux antibiotiques. 2014. http://www.onerba.org.

16. Fabre R, Merens A, Lefebvre F, Epifanoff G, Cerutti F, Pupin H, Tardif D, Cavallo JD, Ternois I. Susceptibility to antibiotics of Escherichia coli isolated from community-acquired urinary tract infections. Med Mal Infect. 2010;40(10):555-9. doi:10.1016/jmedmal201003002 (Epub 2010 Apr 22)

17. Tagajdid MR, Boumhil L, Iken M, Adnaoui M, Benouda A. Resistance to fluoroquinolones and third generation cephalosporin of Escherichia coli isolated from urines. Med Mal Infect. 2010;40(2):70-3. doi:10.1016/jmedmal200810015 (Epub 2008 Dec 6)

18. El Bouamri MC, Arsalane L, Kamouni Y, Berraha M, Zouhair S. Evolution récente du profil épidémiologique des entérobactéries uropathogènes productrices de blactamases à spectre élargi à Marrakech, Maroc. Progrès en Urologie. 2014;(24):1058-62.

19. Abreu AG, Marques SG, Monteiro-Neto V, Goncalves AG. Extendedspectrum beta-lactamase-producing enterobacteriaceae in communityacquired urinary tract infections in Sao Luis, Brazil. Braz J Microbiol. 2013;44(2):469-71. doi:10.1590/S1517-83822013005000038 (eCollection 2013).

20. Bourjilat F, Bouchrif B, Dersi N, Claude JD, Amarouch H, Timinouni M. Emergence of extended-spectrum beta-lactamases-producing Escherichia coli in community-acquired urinary infections in Casablanca, Morocco. J Infect Dev Ctries. 2011;5(12):850-5.

21. Rodriguez-Bano J, Alcala J, Cisneros JM, Grill F, Oliver A, Horcajada JP, Tortola T, Mirelis B, Navarro G, Cuenca M, et al. Escherichia coli producing SHV-type extended-spectrum beta-lactamase is a significant cause of community-acquired infection. J Antimicrob Chemother. 2009;63(4):7814. doi:10.1093/jac/dkp028 (Epub 2009 Feb 17).

22. Yu X, Susa M, Weile J, Knabbe C, Schmid RD, Bachmann TT. Rapid and sensitive detection of fluoroquinolone-resistant Escherichia coli from urine samples using a genotyping DNA microarray. Int J Med Microbiol. 2007;297(6):417-29 (Epub 2007 May 7).

23. Ling TK, Xiong J, Yu Y, Lee CC, Ye H, Hawkey PM. Multicenter antimicrobial susceptibility survey of gram-negative bacteria isolated from patients with community-acquired infections in the People's Republic of China Antimicrob Agents Chemother. 2006;50(1):374-8.

24. Neuhauser MM, Weinstein RA, Rydman R, Danziger LH, Karam G, Quinn JP. Antibiotic resistance among gram-negative bacilli in US intensive care units: implications for fluoroquinolone use. JAMA. 2003;289(7):885-8.

25. Guessennd N, Bremont S, Gbonon V, Kacou-Ndouba A, Ekaza E, Lambert T, Dosso M, Courvalin P. Qnr-type quinolone resistance in extended-spectrum beta-lactamase producing enterobacteria in Abidjan, Ivory Coast. Pathol Biol (Paris). 2008;56(7-8):439-46. doi:10.1016/jpatbio200807025 (Epub 2008 Oct 15) 